\section{BMJ Open} Ophthalmology

\title{
Visual outcomes and complications in infantile cataract surgery: a real - world scenario
}

\author{
Goura Chattannavar, ${ }^{1}$ Akshay Badakere, ${ }^{1}$ Ashik Mohamed (1) , \\ Ramesh Kekunnaya (D) ${ }^{1}$
}

To cite: Chattannavar G, Badakere A, Mohamed A, et al. Visual outcomes and complications in infantile cataract surgery: a real - world scenario. BMJ Open Ophthalmology 2022;7:e000744. doi:10.1136/ bmjophth-2021-000744

\section{- Additional supplemental material is published online only. To view, please visit the journal online (http://dx.doi. org/10.1136/bmjophth-2021- 000744).}

Received 13 February 2021 Accepted 4 February 2022

Check for updates

(C) Author(s) (or their employer(s)) 2022. Re-use permitted under CC BY-NC. No commercial re-use. See rights and permissions. Published by BMJ.

${ }^{1}$ Strabimsus, Pediatric and Neuro-ophthalmology, Jasti V Ramanamma Children's Eye care, Child Sight Institute, LV Prasad Eye Institute, Hyderabad, Telangana, India

${ }^{2}$ Ophthalmic Biophysics, LV Prasad Eye Institute, Hyderabad, Telangana, India

Correspondence to Dr Ramesh Kekunnaya; rameshak@lvpei.org

\section{ABSTRACT}

Objective To evaluate visual outcomes and complications of infantile cataract surgery through a 1year follow-up period in a real world scenario. Methods and analysis Prospective observational study evaluating infants with cataract undergoing surgery. Results We analysed 173 eyes of 97 infants (76 bilateral); median age 18.7 weeks, (IQR: 11-33.9 weeks). Toxoplasmosis, rubella, cytomegalovirus and herpes infection was the most common aetiology in both unilateral $10(47.6 \%)$ and bilateral $43(55.1 \%)$ cases, followed by familial and syndromic cases. Fifty-four eyes (29.5\%) received primary intraocular lens (IOL) implantation. Seventy-five infants $(76 \%)$ were less than 6 months of age. At 1 -year follow-up, mean log MAR best-corrected visual acuity was $1.00 \pm 0.08$ and $1.21 \pm 0.03$ in unilateral and bilateral cases respectively $(p=0.012)$, which was not statistically significant. At 1-year follow-up, pseudophakic $(1.09 \pm 0.05)$ eyes had a better mean log MAR visual acuity comparing aphakes $(1.24 \pm 0.04)$ clinically but was not statistically significant after the application of Bonferroni correction ( $p=0.012$ ). The mean myopic shift of $-2.9 D \pm 0.39$ and $-4.53 D \pm 0.55$ over 1 year was noted in aphakes and pseudophakes, respectively $(p=0.016)$. Visual axis opacification and glaucoma were the most common complications noted in pseudophakes and aphakes, respectively.

Conclusion Primary $10 \mathrm{~L}$ implantation in selected cases of infantile cataract is a feasible option, particularly in cases when optimal aftercare and refractive rehabilitation of aphakia are not possible.

\section{INTRODUCTION}

The first 2 years of a child's life are critical in the development of vision. Lenticular opacities during this phase can suppress primary sensory development leading to amblyopia. As age at cataract surgery is an important factor influencing the visual outcome in children with both unilateral and bilateral cataracts, ${ }^{1}$ it is important to treat and visually rehabilitate these children as early as possible.

The intraocular lens (IOL) implantation in infants below the age of 7 months is controversial. ${ }^{2}$ Although several studies have shown varying results regarding the safety of early IOL implantation, the Infant Aphakia

\section{Key message}

What is already known on this topic?

- Safety of intraocular lens (IOL) implantation in infants above the age of 7 months is well known but, less than 6 months of age is controversial; and there are relatively few prospective studies of outcomes in this age range.

\section{What this study adds?}

- Through this paper we studied the feasibility of IOL implantation children aged between 2 months to 12 months. We found that IOL implantation is possible in selected patients with better safety profile. This will help the children to be visually rehabilitated early especially, in developing countries where compliance to spectacles/contact lens and follow-up is a major issue.

How this study might affect research, practice or policy?

$30 \%$ of the infants in our population fulfilled the study criteria (axial length $\geq 16.5 \mathrm{~mm}$, horizontal corneal diameter $\geq 10.5 \mathrm{~mm}$ ) for primary IOL implantation.

- Further studies are required to assess the safety profile of IOL implantation in remaining $70 \%$ and thus stimulating researchers to study the feasibility of $\mathrm{IOL}$ implantation in all countries especially the IOL power calculation and IOL design for infants younger than 6 months and children with microcornea.

Treatment Study (IATS) suggested that, at 1 year of age, visual outcomes were similar among aphakes, in those who have been given early rehabilitation with contact lenses and pseudophakes. The IATS results also showed a higher complication rate in pseudophakes with a need for secondary intervention. Hence, IATS recommended early IOL implantation in those infants for whom cost and contact lens handling were challenges. ${ }^{3}$ Negalur and associates reported that the primary IOL implantation is safe in infants aged $<6$ months in the absence of conditions such as anterior segment dysgenesis, microcornoea and glaucoma. ${ }^{4}$ With existing challenges due to economic constraints and 
follow-up in developing nations and by weighing the risk-benefit ratio, there is an inclination towards primary IOL implantation.

Visual axis opacification (VAO), glaucoma, retinal detachment and, rarely, endophthalmitis are sightthreatening complications following an infantile cataract surgery. ${ }^{56}$ IATS has reported VAO as the most common complication in pseudophakia, whereas in aphakia, glaucoma is the most common complication. ${ }^{7}$ Overall, glaucoma is the second most commonly reported complication after an infantile cataract surgery. The various risk factors for the development of glaucoma are cataract surgery at a very early age, additional surgery for secondary membrane formation, presence of microcornea, type of cataract and phakic status. ${ }^{89}$ In several studies, presence of IOLs has been recognised as a protective factor against the development of glaucoma..$^{11}$ The objective of our study was to prospectively evaluate visual outcomes and complications following infantile cataract surgery over a 1-year follow-up period.

\section{MATERIALS AND METHODS}

This was a prospective study conducted at L V Prasad Eye Institute, Hyderabad, India. A total of 173 eyes of 97 infants (age range, 4-46 weeks) operated for congenital cataract between June 2016 and June 2017 with a follow-up of 1-year postsurgery were included. A written informed consent explaining the details of evaluation, surgery performed and possible complications associated with surgery and general anaesthesia was obtained from the parents.

All patients were subjected to a comprehensive ocular examination after taking complete history from the parents. The preoperative visual status was recorded whenever possible and strabismus and nystagmus, if present, were documented. An ultrasound B scan was performed in all cases. Under general anaesthesia, axial length (Tomey AL-100, Germany), corneal thickness (Tomey SP-100, Germany), keratometry (Nidek HandyReF-K, Japan) and corneal diameter (Castroviejo callipers) were measured. Gonioscopy (Volk 4 mirror indirect gonio lens) was performed under anaesthesia prior to surgery and anterior chamber angles were labelled as open when posterior pigmented trabecular meshwork was seen. The presence of abnormal iris processes, anterior insertion of iris and extent of peripheral anterior synechiae (PAS), if any, were noted in all eyes.

Lens aspiration with primary posterior capsulotomy and anterior vitrectomy with or without IOL implantation was performed. We did not randomise the patients into aphakia and pseudophakia groups as we wanted to study the real world scenario without any restricting factors. Only eyes which satisfied the criteria of an axial length $\geq 16.5 \mathrm{~mm}$ and a horizontal corneal diameter $\geq 10.5 \mathrm{~mm}$ were implanted with an IOL in the bag (Acrysof SA60AT, Alcon laboratories, Inc, Fort Worth, Tx USA). ${ }^{12}$ The IOL power was calculated using SandersRetzlaff-Kraff II/T formula with Enyedi's guidelines for under-correction. ${ }^{13} 14$ All surgical wounds were sutured with non-absorbable 10-0 nylon sutures. Postoperatively, topical tobramycin $0.3 \%$ or moxifloxacin $0.5 \%$ four times a day for 1 week, atropine sulfate $1 \%$ twice daily for 1 week and a tapering dose of prednisolone acetate $1 \%$ 8-12 times daily with a gradual tapering over 6 weeks were prescribed to all infants.

The children were examined on first postoperative day and, under general anaesthesia, at 1 week during which sutures were removed and glasses or contact lenses were prescribed. The children were followed up at one, six and 12 months postsurgery. Age-appropriate visual acuity testing methods were followed. In children where visual acuity could not be estimated by these methods, visual behaviour and their ability to fix and follow light were assessed. Teller Acuity Charts (TAC, Stereo Optical Chicago, Illinois, USA) were used for assessing grating visual acuity at 1 year of age. When a child resisted occlusion during monocular vision recording, binocular grating acuity was recorded. Intraocular pressure (IOP) was measured with Perkins tonometer (Haag-Streit, UK) when under anaesthesia and Icare tonometer (TA01i, Finland) in the outpatient department. Retinoscopy was performed by a trained optometrist. All children operated for bilateral cataracts were rehabilitated with spectacles and children with unilateral aphakia were offered contact lenses. In cases of non-compliance to contact lens, spectacles were given for constant wear. Amblyopia therapy was initiated from 1 week after surgery. Additionally, gonioscopy, keratometry, corneal thickness, axial length and corneal diameter were also documented at 1 year follow-up.

Strabismus, if present, was measured using prism bar cover test (if the child allowed examination) or a modified Krimsky test. Nystagmus, if present, was also documented. In addition, VAO, signs of inflammation, position of IOL and posterior segment complication, if any, were noted in every visit. A diagnosis of glaucoma was made if IOP was $>20 \mathrm{~mm} \mathrm{Hg}$ with one or more of the following changes that is, increase in corneal diameter, asymmetric progressive myopic shift coupled with increase in corneal diameter and/or increase in axial length and an increased cup to disc ratio of the optic nerve head. A patient was designated as a glaucoma suspect if they had two consecutive IOP readings $\geq 20 \mathrm{~mm}$ $\mathrm{Hg}$ on two different visits without any other anatomical changes.

Statistical analysis was performed using STATA V.14.2 (StataCorp). A linear mixed effects model using maximum likelihood estimation with random intercepts at the subject level was used in the data analysis to account for the correlation between fellow eyes of the same subject. The comparisons between postoperative visits or groups (aphakic vs pseudophakic or unilateral vs bilateral) were evaluated by mixed effects regression analysis using marginal linear predictions. A $p<0.05$ was considered statistically significant. For multiple comparisons, a Bonferroni correction was made. 


\section{RESULTS}

One hundred and twelve patients under the age of 12 months (median age: 14.5 weeks and IQR: 9.3-32.2 weeks) were enrolled in the study. Fifteen patients were excluded as they either did not undergo surgery at our centre or were lost to follow-up after surgery. Finally, a total of 173 eyes belonging to 97 patients $(86.6 \%)$ were included. Fifty subjects $(51.6 \%)$ were females and 76 $(78.4 \%)$ had bilateral cataract.

TORCH infection (Toxoplasmosis, Rubella, Cytomegalovirus and Herpes virus infections) was the most common aetiology in both unilateral $(\mathrm{n}=10,47.6 \%)$ and bilateral $(n=43,55.1 \%)$ cataracts, followed by familial and syndromic cases. Overall, cytomegalovirus infection was the predominant $(n=21,21 \%)$ TORCH infection, followed by mixed infection $(\mathrm{n}=19,19 \%)$, rubella virus infection $(n=8,8 \%)$ and herpes virus infection $(n=5$, $5 \%$ ). The number of patients with undetermined causes was $18(23.1 \%)$ and $9(11.5 \%)$ in bilateral and unilateral cataracts, respectively. Two eyes $(9.5 \%)$ of 21 unilateral cataracts had persistent fetal vasculature. Of 26 infants diagnosed with rubella cataract, 7 (26.9\%) infants underwent IOL implantation, while 24 of 71 (33.8\%) non-rubella aetiology cataracts underwent IOL implantation.

The mean age at surgery was 23.7 weeks (median: 18.7 weeks and IQR: $11-33.9$ weeks). Of 173 eyes that underwent surgery, 54 eyes $(29.5 \%)$ were implanted with IOLs. The IOL status in unilateral and bilateral cases is summarised in online supplemental table 1. Of 97 patients who were operated, $94(96.9 \%), 91(93.8 \%)$ and $65(67.0 \%)$ followed up at 1 week, 1 month and 6 months, respectively. When there was a follow-up attrition, each patient was given a telephonic reminder call within a week of their missed follow-up and only patients who reviewed to clinic within 2 weeks of telephonic call were included in further analysis. At 1 year, the follow-up rate continued to drop to 53 patients $(54.6 \%)$, but improved to 79 patients $(81.4 \%)$ following a reminder telephone call after non-attendance.

Best-corrected visual acuity (BCVA) outcomes and myopic shift are tabulated in table 1 . Grating acuity in LogMAR equivalents was achieved for 123 eyes, visual fixation behaviour was recorded in the remainder. Binocular measurements only were possible in $53(43 \%)$ eyes but included in the analysis as most of these eyes were of bilateral cataract and had not resisted occlusion of either eyes. When there was a resistance to occlusion of either eye, efforts were made to assess monocular visual acuity. There was no significant difference in mean LogMAR BCVA between unilateral and bilateral cases or aphakic and pseudophakic eyes (table 1). A myopic shift was recorded in all eyes, with no significant difference in dioptric power change between aphakic and pseudophakic eyes (table 1). Figure 1 shows mean spherical equivalent refraction at all postoperative visits.

The secondary outcomes such as corneal diameter, central corneal thickness, keratometry and axial length 


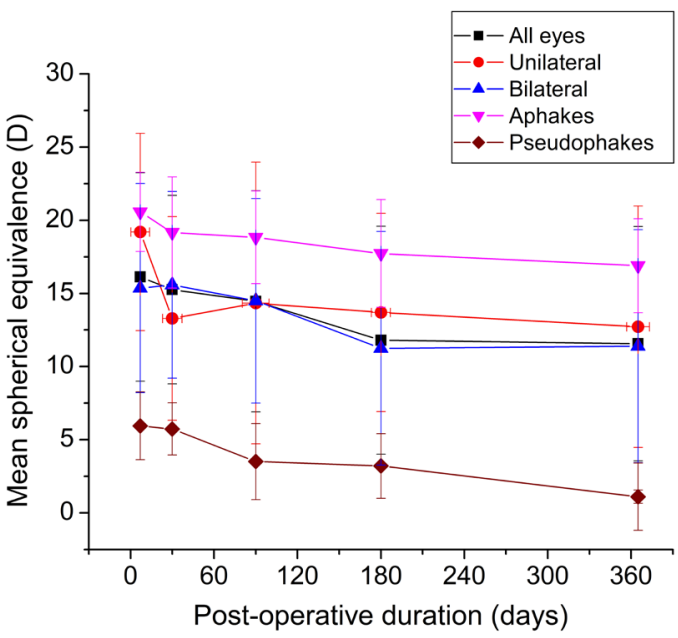

Figure 1 Follow-up trend of mean spherical equivalent in unilateral, bilateral, aphakes and pseudophakes.

at 1 year were compared with preoperative values, and evaluated for aphakes and pseudophakes as well as unilateral and bilateral cataracts (table 2).

Gonioscopy was documented in 103 eyes $(59.5 \%)$ preoperatively and in 67 eyes $(38 \%)$ at 1 year. Preoperatively, a majority of eyes had open angles $(99,96.1 \%)$ and 4 eyes $(3.9 \%)$ showed closed angles. At 1 year postoperatively, 64 eyes (37\%) had open angles of which prominent iris processes were seen in 9 eyes $(13 \%)$ and pigmented posterior trabecular meshwork in 23 eyes (34\%). Three eyes $(4 \%)$ had closed angles and showed PAS. Although no IOP spike was noted in any of the eyes with increased pigmentation, the subsequent course of these eyes in developing glaucoma has to be monitored closely.

While 11 infants $(11.3 \%)$ presented with strabismus prior to surgery, 34 (34\%) were noted to have strabismus at the end of the study. Esotropia $(22 \%-65 \%)$ was the most common strabismus (range, $8-50$ prism dioptres or $\mathrm{PD})$ as compared with exotropia (12\%-35\%, range $13-40$ PD). None of the eyes underwent strabismus surgery. Nystagmus was noted in 43 patients $(44.3 \%)$.

Surgical complications in each group are recorded in table 3. The occurrence of VAO was significantly higher in the pseudophakic group at $22.2 \%$ compared with (4.2\% in aphakic group). Out of 173 eyes, 18 (10.3\%) underwent a secondary surgery (table 4 ). Twelve of the 17 cases $(70.6 \%)$ with VAO, were visually significant and warranted membranectomy, the most common secondary procedure performed. No significant difference in the occurrence of complications or the need for secondary surgery were found between unilateral and bilateral cases (online supplemental tables 2 and 3).

Of the two eyes (1\%) that developed endophthalmitis, one eye presented 1 month postoperatively with a surgical site infiltrate. The other eye presented as chronic endophthalmitis at 8 months postoperatively. Both cases of chronic endophthalmitis occurred in babies who had been lost to routine follow-up.

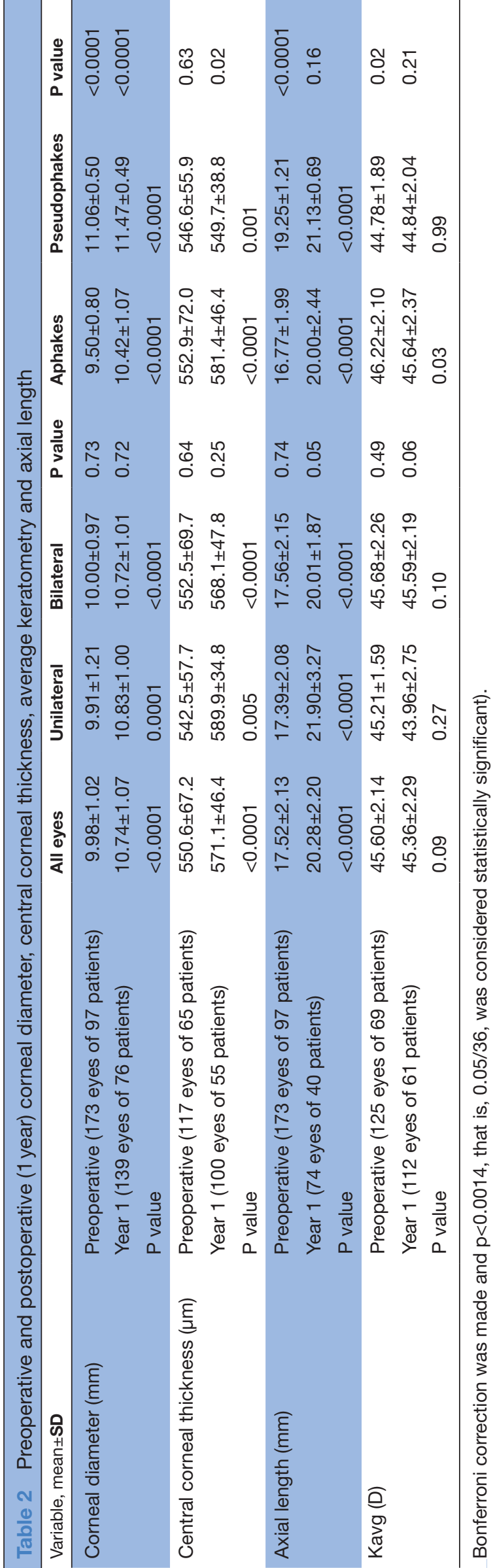


Table 3 Postoperative complications in aphakic and pseudophakic groups

\begin{tabular}{|c|c|c|c|}
\hline Postoperative complication $\mathrm{n},(\%, 95 \% \mathrm{Cl})$ & $\begin{array}{l}\text { Aphakes } \\
\text { (119 eyes) }\end{array}$ & $\begin{array}{l}\text { Pseudophakes } \\
\text { (54 eyes) }\end{array}$ & $P$ value \\
\hline Visual axis opacification & $5(4.2 \%, 1.6 \%$ to $10 \%)$ & $12(22.2 \%, 12.5 \%$ to $35.9 \%)$ & 0.0004 \\
\hline Secondary glaucoma & $6(5.0 \%, 2.1 \%$ to $11.1 \%)$ & $1(1.9 \%, 0.1 \%$ to $11.2 \%)$ & 0.37 \\
\hline Endophthalmitis & $1(0.8 \%, 0.04 \%$ to $5.3 \%)$ & $1(1.9 \%, 0.1 \%$ to $11.2 \%)$ & 0.56 \\
\hline Vitreous in anterior chamber & $1(0.8 \%, 0.04 \%$ to $5.3 \%)$ & $0(0 \%, 0 \%$ to $8.3 \%)$ & 0.50 \\
\hline Corneal decompensation & $0(0 \%, 0 \%$ to $3.9 \%)$ & $1(1.0 \%, 0.1 \%$ to $11.2 \%)$ & 0.13 \\
\hline Vitreous haemorrhage & $2(1.7 \%, 0.3 \%$ to $6.5 \%)$ & $0(0 \%, 0.1 \%$ to $11.2 \%)$ & 0.34 \\
\hline Total & $15(12.6 \%, 7.5 \%$ to $20.3 \%)$ & $14(25.9 \%, 15.4 \%$ to $39.9 \%)$ & 0.04 \\
\hline
\end{tabular}

Bonferroni correction was made and $p<0.007$, that is, $0.05 / 7$, was considered statistically significant.

\section{DISCUSSION}

This prospective study adds to existing literature, a large cohort of infants who underwent cataract surgery with a reasonably good follow up. The salient feature of our study was the congenital cataract cohort group was not randomised and were studied in a natural course as we wanted to prospectively look into the outcomes without any restrictive factors in a developing nation, unlike the existing literature on randomised studies in developed nations. Bilateral cataracts were predominant in our study in contrast to studies from developed nations where more unilateral infantile cataracts have been reported. ${ }^{515}$ The goal of this study was not to compare the complications between aphakes and pseudophakes, but rather to see the practical feasibility of IOL implantation, visual outcomes and report complications (if any) in both groups.

Majority of the infants in our study were females, unlike studies by Eckstein and associates, implying a shifting trend towards gender parity and an increase in awareness among the population. ${ }^{15}$ More than three-quarters of the patients in our study had presented before 6 months of age implying increasing awareness and regular screening of infants. While Foster et al and Eckstein et al reported most cataracts as idiopathic in aetiology ${ }^{15}{ }^{16}$ Our study showed that TORCH infection was the most common in both unilateral and bilateral cases. One-third of the children presented, had high-risk systemic conditions such as congenital heart disease and seizure disorder.
The mean age at surgery in our study was 23.7 weeks which was higher compared with the study done by Autrata and associates, where it was 12.4 weeks. ${ }^{17}$ In IATS, the mean age at surgery was 7.2 weeks. The optimal method for visual rehabilitation for children following cataract surgery remains debatable. In recent years, there has been an increase in the use of IOLs to correct aphakia during infancy. ${ }^{17} 18$ One-third of the eyes in our study satisfied the criteria for IOL implantation and were successfully implanted with a posterior chamber IOL. The remaining two-thirds were prescribed either spectacles or contact lenses.

The study by Chougule and associates has reported a loss of follow-up from $85 \%$ at 1-month postsurgery to $52 \%$ at the end of 1 year. ${ }^{19}$ In our study, despite regular reminders for follow-ups through telephone calls and text messages, the rate of follow-ups dropped from almost $100 \%$ on the first postoperative day to $50 \%$ at 6 months. After persistent telephone calls and explaining the need for follow-up and examination, the rate of follow-up increased to $80 \%$ at 1 year.

At 1 year, there was no significant difference in mean BCVA in implanted eyes compared with non-implanted eyes. Unlike IATS and IOL under two study which strongly discourage IOL implantation in infants less than 6 months of age owing to higher adverse effect at 5 years, our study by Chougule and associates showed implantation of IOL in carefully selected cases as an viable option in developing countries. ${ }^{12}$ Autrata et al had shown in their

\begin{tabular}{llcl}
\hline Table 4 Second surgery in aphakic and pseudophakic groups & & \\
\hline Secondary surgery $\mathbf{n},(\%, 95 \% \mathbf{C l})$ & $\begin{array}{l}\text { Aphakes } \\
\text { (119 eyes) }\end{array}$ & $\begin{array}{l}\text { Pseudophakes } \\
\text { (54 eyes) }\end{array}$ & P value \\
\hline Membranectomy & $3(2.5 \%, 0.7 \%$ to $7.7 \%)$ & $9(16.7 \%, 8.4 \%$ to $29.8 \%)$ & 0.001 \\
\hline Trabeculectomy +trabeculotomy & $2(1.7 \%, 0.3 \%$ to $6.5 \%)$ & $0(0 \%, 0 \%$ to $8.3 \%)$ & 0.34 \\
Vitrectomy & $2(1.7 \%, 0.3 \%$ to $6.5 \%)$ & $0(0 \%, 0 \%$ to $8.3 \%)$ & 0.34 \\
Vitrectomy+intraocular antibiotics & $1(0.8 \%, 0.04 \%$ to $5.3 \%)$ & $1(1.9 \%, 0.1 \%$ to $11.2 \%)$ & 0.56 \\
Intraocular lens explantation & $\mathrm{N} / \mathrm{A}$ & $1(1.9 \%, 0.1 \%$ to $11.2 \%)$ & $\mathrm{N} / \mathrm{A}$ \\
\hline Total & $8(6.7 \%, 3.2 \%$ to $13.2 \%)$ & $10(18.5 \%, 9.7 \%$ to $31.9 \%)$ & 0.02 \\
\hline
\end{tabular}

Bonferroni correction was made and $p<0.01$, that is, $0.05 / 5$, was considered statistically significant.

$\mathrm{N} / \mathrm{A}$, not available. 
study of unilateral cataracts that the mean final visual of the operated eye was $0.43 \pm 0.33$ for the IOL group and $0.58 \pm 0.39$ for the CL group $(\mathrm{p}=0.14)$ while the mean interocular difference in visual acuity was $0.22 \pm 0.29$ for the IOL group and $0.56 \pm 0.31$ for the CL group $(\mathrm{p}=0.042)$. Thus, they had concluded that the correction of aphakia after cataract surgery with primary IOL implantation resulted in improved visual acuity. ${ }^{17}$ Similar to our results, IATS had shown that the median visual acuity at 12 months after cataract surgery was the same for both aphakia and the IOL cohorts (aphakia group $0.80 \log$ MAR, IOL group $0.97 \log$ MAR; $p=0.19) .{ }^{20} \mathrm{IOL}$ under-2 study had looked into the effectiveness of IOL implantation in children less than 2 years of age and had found that IOL implantation had significant better vision compared with children who were left aphakic, but this result was consistent only in bilateral cataracts and not in unilateral cataracts. ${ }^{21}$

We found that the average myopic shift was similar in both the groups and emmetropisation was faster in pseudophakes compared with aphakes.

Among the secondary outcomes, the corneal diameter increased significantly in both aphakes and pseudophakes. There was an increase in central corneal thickness 1-year post surgery when compared with the immediate postoperative period. These results are consistent with the results of earlier studies. ${ }^{22-24}$ While the myopic shift was significant in pseudophakes, a significant change in axial length was noted in both groups; similar to the IATS study. ${ }^{25}$ Differing results have been reported on the axial growth of the eye after cataract surgery during infancy. ${ }^{26} 27$

The most common complication noted in our study was VAO followed by secondary glaucoma. The rate of complications and second surgery were more in pseudophakes compared with aphakes. VAO following cataract surgery can range from $40 \%$ to $95 \%$. Trivedi and associates reported that $25 \%$ of their cases with VAO required a second surgery. ${ }^{28}$ However, in our study, VAO was noted in $9.8 \%$ of patients and was predominant in pseudophakes. More than $70 \%$ of the eyes that developed VAO underwent membranectomy. In common with the findings from other studies, VAO was significantly more common in implanted eyes than aphakic eyes as was the requirement for further surgery. This incidence was much lower compared with the previous studies and could be attributed to using a hydrophobic acrylic lens, in the bag lens implantation, a thorough cortical clean up and an intense postoperative topical steroid regimen.

In contrast to the IATS study, 3\% of infants were labelled as glaucoma suspects and $4 \%$ were treated for glaucoma, and fewer pseudophakes developing glaucoma, suggesting a possible protective role of the IOL as has been suggested in some studies. ${ }^{9}{ }^{29}$ Endophthalmitis is rare after paediatric cataract surgery with an estimated prevalence of $0.07 \% .^{30}$

Two babies who had been lost to follow-up returned with endophthalmitis. While one developed endophthalmitis
1 month postoperatively and had a suture site infiltrate, the other presented at 8 months postoperatively with chronic endophthalmitis. Microbiological work up did not reveal any organisms. Both the children were given intravitreal antibiotics without any delay and followed up subsequently.

The major limitation in our study was the follow-up attrition and hence the parameters evaluated were corrected for age and analysed. Due to high-risk systemic conditions, the anaesthesia time had to be shortened and in few cases the biometry readings were not available during the follow-up period. We did not select unilateral or bilateral cataracts in particular as cohort and also did not randomise the patients for aphakia or pseudophakia group as we wanted to study the real life scenario without any restricting factors.

\section{CONCLUSION}

Unlike many other studies of infantile cataract surgery, the most frequent aetiology of cataract in the studied cohort in India was TORCH infection. While there is debate regarding primary IOL implantation in infants less than 6 months' of age, our large cohort suggests that it is feasible in nearly one third of infants: important criteria being the absence of anterior segment pathology, a minimum axial length of $16.5 \mathrm{~mm}$ and horizontal corneal diameter of at least $10.5 \mathrm{~mm}$. In this cohort, eyes which had primary IOL implantation had comparable BCVA at 1 year to aphakic eyes, however, they had a significantly increased incidence of complications and subsequent surgery. Given these findings, the decision to implant should be balanced against potential attendance issues and compliance with optical correction of aphakia in developing nations, the issues with attendance and optical rehabilitation in low-income and middle-income countries and may tip the balance in favour of early IOL implantation.

Contributors Contributor ship statement: GC: planning, acquisition of data or analysis and interpretation of data, AM planning, acquisition of data or analysis and interpretation of data, draft, revision: $A B$ acquisition of data or analysis and interpretation of data, revision: RK: conduct, reporting, conception and design, Draft, revision, supervision and guarantor.

Funding Hyderabad Eye Research Foundation, Hyderabad, India.

Competing interests None declared.

Patient and public involvement Patients and/or the public were involved in the design, or conduct, or reporting, or dissemination plans of this research. Refer to the Methods section for further details.

Patient consent for publication Not applicable.

Ethics approval The study was approved by the Institutional Ethics Committee and adhered to the tenets of the Declaration of Helsinki (LEC 06-16-046).

Provenance and peer review Not commissioned; externally peer reviewed.

Data availability statement Data are available on reasonable request.

Supplemental material This content has been supplied by the author(s). It has not been vetted by BMJ Publishing Group Limited (BMJ) and may not have been peer-reviewed. Any opinions or recommendations discussed are solely those of the author(s) and are not endorsed by BMJ. BMJ disclaims all liability and responsibility arising from any reliance placed on the content. Where the content includes any translated material, BMJ does not warrant the accuracy and reliability 
of the translations (including but not limited to local regulations, clinical guidelines, terminology, drug names and drug dosages), and is not responsible for any error and/or omissions arising from translation and adaptation or otherwise.

Open access This is an open access article distributed in accordance with the Creative Commons Attribution Non Commercial (CC BY-NC 4.0) license, which permits others to distribute, remix, adapt, build upon this work non-commercially, and license their derivative works on different terms, provided the original work is properly cited, appropriate credit is given, any changes made indicated, and the use is non-commercial. See: http://creativecommons.org/licenses/by-nc/4.0/.

ORCID iDs

Ashik Mohamed http://orcid.org/0000-0001-5520-4930

Ramesh Kekunnaya http://orcid.org/0000-0001-5789-2300

\section{REFERENCES}

1 Lesueur LC, Arné JL, Chapotot EC, et al. Visual outcome after paediatric cataract surgery: is age a major factor? Br J Ophthalmol 1998;82:1022-5

2 Kumar P, Lambert SR. Evaluating the evidence for and against the use of IOLs in infants and young children. Expert Rev Med Devices 2016;13:381-9.

3 Infant Aphakia Treatment Study Group, Lambert SR, Buckley $E G$, et al. A randomized clinical trial comparing contact lens with intraocular lens correction of monocular aphakia during infancy: grating acuity and adverse events at age 1 year. Arch Ophthalmol 2010;128:810-8.

4 Negalur M, Sachdeva V, Neriyanuri S, et al. Long-term outcomes following primary intraocular lens implantation in infants younger than 6 months. Indian J Ophthalmol 2018;66:1088-93.

5 Khanna RC, Foster A, Krishnaiah S, et al. Visual outcomes of bilateral congenital and developmental cataracts in young children in south India and causes of poor outcome. Indian J Ophthalmol 2013;61:65-70.

6 Khokhar SK, Pillay G, Dhull C, et al. Pediatric cataract. Indian J Ophthalmol 2017;65:1340-9.

7 Plager DA, Lynn MJ, Buckley EG, et al. Complications, adverse events, and additional intraocular surgery 1 year after cataract surgery in the infant Aphakia Treatment Study. Ophthalmology 2011;118:2330-4.

8 Trivedi $\mathrm{RH}$, Wilson ME, Golub RL. Incidence and risk factors for glaucoma after pediatric cataract surgery with and without intraocular lens implantation. J Aapos 2006;10:117-23.

9 Mataftsi A, Haidich A-B, Kokkali S, et al. Postoperative glaucoma following infantile cataract surgery: an individual patient data metaanalysis. JAMA Ophthalmol 2014;132:1059-67.

10 Asrani S, Freedman S, Hasselblad V, et al. Does primary intraocular lens implantation prevent "aphakic" glaucoma in children? J Aapos 2000;4:33-9.

11 Lawrence MG, Kramarevsky NY, Christiansen SP, et al. Glaucoma following cataract surgery in children: surgically modifiable risk factors. Trans Am Ophthalmol Soc 2005;103:46-55

12 Chougule P, Kekunnaya R. Intraocular lens implantation in infants and toddlers in 2020. Expert Rev Ophthalmol 2020;15:275-84.
13 Sachdeva V, Katukuri S, Kekunnaya R, et al. Validation of Guidelines for Undercorrection of Intraocular Lens Power in Children. Am J Ophthalmol 2017;174:17-22.

14 Kekunnaya R, Gupta A, Sachdeva V, et al. Accuracy of intraocular lens power calculation formulae in children less than two years. Am J Ophthalmol 2012;154:13-19.

15 Eckstein M, Vijayalakshmi P, Killedar M, et al. Aetiology of childhood cataract in south India. Br J Ophthalmol 1996;80:628-32.

16 Foster A, Gilbert C, Rahi J. Epidemiology of cataract in childhood: a global perspective. J Cataract Refract Surg 1997;23 Suppl 1:601-4.

17 Autrata R, Rehurek J, Vodicková K. Visual results after primary intraocular lens implantation or contact lens correction for aphakia in the first year of age. Ophthalmologica 2005;219:72-9.

18 Lambert SR, Lynn M, Drews-Botsch C, et al. Intraocular lens implantation during infancy: perceptions of parents and the American Association for Pediatric Ophthalmology and Strabismus members. J Aapos 2003;7:400-5.

19 Chougule P, Murat S, Mohamed A, et al. Follow-up patterns and associated risk factors after paediatric cataract surgery: observation over a 5-year period. Br J Ophthalmol 2018;102:1550-5.

20 Lambert SR, Lynn M, Drews-Botsch C, et al. A comparison of grating visual acuity, strabismus, and reoperation outcomes among children with aphakia and pseudophakia after unilateral cataract surgery during the first six months of life. J Aapos 2001;5:70-5.

21 Solebo AL, Russell-Eggitt I, Cumberland PM, et al. Risks and outcomes associated with primary intraocular lens implantation in children under 2 years of age: the loLunder2 cohort study. $\mathrm{Br} J$ Ophthalmol 2015;99:1471-6.

22 Resende GM, Lupinacci APC, Árieta CEL, et al. Central corneal thickness and intraocular pressure in children undergoing congenita cataract surgery: a prospective, longitudinal study. $\mathrm{Br} J$ Ophthalmol 2012;96:1190-4.

23 Lim Z, Muir KW, Duncan L, et al. Acquired central corneal thickness increase following removal of childhood cataracts. Am J Ophthalmol 2011;151:434-41.

24 Muir KW, Duncan L, Enyedi LB, et al. Central corneal thickness: congenital cataracts and aphakia. Am J Ophthalmol 2007;144:502-6.

25 Lambert SR, Lynn MJ, DuBois LG, et al. Axial elongation following cataract surgery during the first year of life in the infant Aphakia Treatment Study. Invest Ophthalmol Vis Sci 2012;53:7539-45.

26 O'Keefe M, Fenton S, Lanigan B. Visual outcomes and complications of posterior chamber intraocular lens implantation in the first year of life. J Cataract Refract Surg 2001;27:2006-11.

27 Dahan E, Drusedau MU. Choice of lens and dioptric power in pediatric pseudophakia. J Cataract Refract Surg 1997;23 Suppl 1:618-23.

28 Trivedi RH, Wilson ME, Bartholomew LR, et al. Opacification of the visual axis after cataract surgery and single acrylic intraocular lens implantation in the first year of life. J Aapos 2004;8:156-64.

29 Beck AD, Freedman SF, Lynn MJ, et al. Glaucoma-related adverse events in the Infant Aphakia Treatment Study: 1-year results. Arch Ophthalmol 2012;130:300-5.

30 Wheeler DT, Stager DR, Weakley DR. Endophthalmitis following pediatric intraocular surgery for congenital cataracts and congenital glaucoma. J Pediatr Ophthalmol Strabismus 1992;29:139-41. 